Check for updates

Cite this: RSC Adv., 2019, 9, 21192

\title{
Nitrogen/phosphorus synergistic flame retardant- filled flexible polyurethane foams: microstructure, compressive stress, sound absorption, and combustion resistance
}

\author{
Ting-Ting Li, abc Mengfan Xing, ${ }^{a}$ Hongyang Wang, ${ }^{a}$ Shih-Yu Huang, ${ }^{\text {tbd }}$ Chengeng Fu, ${ }^{a}$ \\ Ching-Wen Lou ${ }^{\text {adefg }}$ and Jia-Horng Lin (D) *abcdghij
}

Compared with a rigid polyurethane foam, a flexible polyurethane foam (FPUF) has more diversified applications including filtration, sound absorption, vibration-proofing, decoration, packaging, and heat insulation. However, its most potential hazard is flammability. Therefore, in this study, we focused on improving its flame retardation and then tested its sound absorption with the addition of nitrogen/ phosphorus synergistic flame retardants. The influence of phosphorus-based flame retardants (TCPP, TDCP, and V6) and a nitrogen/phosphorus synergistic flame retardant (melamine-TDCP) on its microstructure, compressive stress, sound absorption, thermal stability, and flame retardation was systematically explored. The presence of phosphorus flame retardants improved the sound absorption but considerably decreased the mechanical properties. The melamine-TDCP compound flame retardant delivered smaller cells and thus increased the compression property of the resulting foam. Moreover, with a higher content of melamine, the initial mass-loss temperature also increased. In particular, on using TDCP and $5 \mathrm{wt} \%$ of melamine as flame retardants, the compressive stress increased by 3.4 times, the average sound absorption coefficient was 0.45 , and LOI reached 25.5 , which met the requirements of industrial flame retardant/sound absorbent materials. This resultant flame retardant/sound absorbent flexible polyurethane foam can serve as a mattress and furniture pad material, vehicle seat cushion material, and liner for laminated composites in the future.

Received 27th March 2019 Accepted 4th June 2019

DOI: 10.1039/c9ra02332a

rsc.li/rsc-advances conductivity. Compared with a rigid polyurethane foam, it has more diversified applications as a thermal barrier in the appliance industry and as a cushioning material; moreover, it can be used in mattresses, heat insulation pipes, automobile interiors, energy absorption, oil/heavy metal adsorption, vibration-proof packaging, construction, decoration, building roofs, and filtration..$^{1-5}$

The most potential hazard of FPUF is its flammability. Neat FPUF is combustible, and its LOI is lower than $19 .{ }^{6}$ When FPUF is ignited, it easily decomposes and releases carbon monoxide, hydrogen cyanide, and other toxic byproducts. ${ }^{7}$ This feature restricts the applications of FPUF in the construction field and engages scholars to improve its flame retardation property. ${ }^{8}$ Many studies have been conducted to improve the combustion resistance of FPUF by adding flame retardants. A common method involves the addition of halogenated flame retardants into the polyurethane (PU) foam. A halogenated flame retardant is one of the most commonly used additives in the PU material industry. However, these flame retardants have been confirmed to release an environmentally harmful toxic gas, halogen hydride, after combustion. ${ }^{9}$ Therefore, other types of flame retardants have been developed to replace these halogen flame 
retardants, and these include phosphorus, silicon and nitrogen compounds. Chen et al. ${ }^{9}$ synthesized a halogen-free phosphorus-containing triol flame retardant phosphoryltrimethanol (PTMA). They showed that after the addition of PTMA into FPUF, the LOI value increased with the content of PTMA and reached a maximum of 22.5. In addition, Rao et al. ${ }^{10,11}$ synthesized two new types of flame retardants, namely, dimethyl methylphosphonate (DMOP) and phosphoruscontaining polyol (PDEO), and the maximum LOI values of FPUF filled with these materials increased to 22.5 and 23.0, respectively.

Besides, some researchers also tried to compound two different kinds of flame retardants to further improve the combustion resistance of FPUF. In these studies, the researchers mostly compounded dimethyl methylphosphonate (DMMP) with other inorganic or organic flame retardants. Chen et al. ${ }^{12}$ combined DMMP with organic melamine to form a halogen-free flame retardant, and the LOI value reached 25 . Czuprynski et al. ${ }^{13}$ compounded the inorganic flame retardant aluminum hydroxide with 15\% DMMP and filled it into FPUF. The LOI value of the reported FPUF material was as high as 25.8. However, these DMMP compounds have relatively higher prices than the common flame retardants such as phosphorus compounds. Moreover, the addition of flame retardants inevitably causes loss of mechanical property. Therefore, in order to maintain the mechanical strength and increase the combustion resistance of FPUF, in this study, we proposed a flame-resistant FPUF that consisted of a nitrogen/phosphorus flame retardant. The influence of phosphorus-based flame retardants (TCPP, TDCP, and V6) and a nitrogen/phosphorus synergistic flame retardant (melamine-TDCP) on the microstructure, compressive stress, sound absorption, thermal stability, and flame retardation was systematically explored. This study will provide a manufacturing process to produce FPUF featuring flame retardant and sound absorbing properties for industrial use.

\section{Experimental}

\subsection{Materials}

Polyether polyol (A agent, CST-1076A) has a specific weight of $1.05 \mathrm{~g} \mathrm{~cm}^{-3}$, hydroxyl value of $450 \pm 20 \mathrm{mg} \mathrm{KOH} / \mathrm{g}$, and viscosity of $3000-6000 \mathrm{mPa}$ s. Methylene bisphenyl isocyanate (MDI, B agent, CST-1076B) has a specific weight of $1.25 \mathrm{~g} \mathrm{~cm}^{-3}$ and viscosity of $200 \pm 50 \mathrm{cps}\left(25^{\circ} \mathrm{C}\right)$. Both of them were provided by Keshengda Trading, China. The -NCO group in MDI reacted with the $-\mathrm{OH}$ in polyol with the help of water as the blowing agent, forming a flexible polyurethane foam (FPUF). Three phosphorus flame retardants TCPP, TDCP, and V6 were provided by Jiangsu Yoke Technology Co., Ltd., China (Fig. 1), and the nitrogen flame retardant melamine was purchased from Tianjin Kemiou Chemical Reagent Co., China. The chemical name, chemical state, decomposition temperature, viscosity, phosphorus content and chlorine content of these three phosphorus flame retardants are displayed in Table 1 . Melamine, known as 1,3,5-triazine-2,4,6-triamine, is a kind of triazine nitrogen-containing heterocyclic organic compound; it is a white reactive powder with a decomposition temperature of $600{ }^{\circ} \mathrm{C}$.

\subsection{Preparation of samples}

FPUF was composed of agent A (i.e., polyether polyol) and agent B (i.e., MDI). Three series of flame retardants were added to agent A, forming phosphorus, melamine-based, and nitrogen/ phosphorus agents, as shown in Table 2. Phosphorus agent A: the phosphorus flame retardants (i.e., V6, TDCP, and TCPP)

Table 1 Compositions of phosphorus flame retardants

\begin{tabular}{|c|c|c|c|c|c|c|}
\hline Name & Chemical name & Chemical state & $\begin{array}{l}\text { Decomposition } \\
\text { temperature } /{ }^{\circ} \mathrm{C}\end{array}$ & Viscosity/cps & $\begin{array}{l}\text { Phosphorus } \\
\text { content/\% }\end{array}$ & $\begin{array}{l}\text { Chlorine } \\
\text { content/\% }\end{array}$ \\
\hline TCPP & Tris(2-chloropropyl)phosphate & Colorless liquid & 300 & $64-70$ & $\geq 9.4 \pm 0.4$ & 32.4 \\
\hline V6 & $\begin{array}{l}\text { Tetrakis(2-chloroethyl)-2, } \\
\text { 2-di(chloromethyl)-1,3 propylene diph }\end{array}$ & Colorless liquid & 200 & $1600-1900$ & $\geq 7.2 \pm 0.3$ & 49.4 \\
\hline
\end{tabular}
2-di(chloromethyl)-1,3 propylene diphosphate
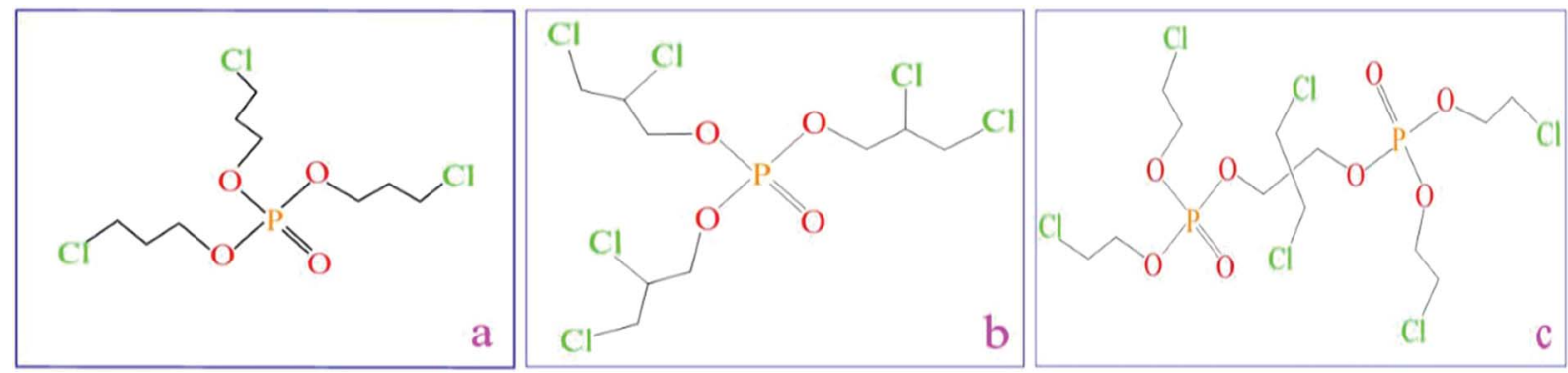

Fig. 1 Chemical formulation of phosphorus flame retardants: (a) TCPP flame retardant, (b) TDCP flame retardant, and (c) V6 flame retardant. 
Table 2 Compositions of flexible polyurethane foam ${ }^{a}$

\begin{tabular}{|c|c|c|c|c|c|c|c|c|c|c|}
\hline Sample code & Control & V6 & TDCP & TCPP & N-5\% & $\mathrm{N}-10 \%$ & P-Mel-1\% & P-Mel-2\% & P-Mel-3\% & P-Mel-5\% \\
\hline $\begin{array}{l}\text { Content of phosphorus flame retardant } \\
\text { (wt\%) }\end{array}$ & 0 & $15 \%$ & $15 \%$ & $15 \%$ & 0 & 0 & TDCP 15\% & TDCP 15\% & TDCP 15\% & TDCP 15\% \\
\hline
\end{tabular}

were individually blended with $180 \mathrm{~g}$ of polyether polyol. Melamine-based agent A: 5 and $10 \mathrm{wt} \%$ of melamine compounds were separately mixed with $180 \mathrm{~g}$ of polyether polyol at $1200 \mathrm{rpm}$ for 15 seconds. Nitrogen/phosphorus agent A: $15 \%$ of TDCP and $180 \mathrm{~g}$ of polyether polyol were blended first, after which $1,2,3$, or $5 \mathrm{wt} \%$ of melamine was added with another fifteen seconds of mixing. Afterward, the three series of agent As were separately blended with $60 \mathrm{~g}$ of isocyanate in a blender at the rate of $1200 \mathrm{rpm}$ for 3 seconds. The mixtures were infused into a closed-type metallic mold prior to the application of a release agent for foaming. FPUFs having thickness of $2 \mathrm{~cm}$ were removed from the mold, placed in a blast drying oven at $37^{\circ} \mathrm{C}$ and cured for 2 hours (Fig. 2).

\subsection{Tests}

2.3.1 Scanning electron microscopy (SEM). The morphology of the original samples was observed with a scanning electron microscope (TM3030, HITACHI, Japan). Samples were cut into fragments and then sputter-coated with gold for SEM observations. The accelerating voltage was $15 \mathrm{kV}$, and the magnification was set at $60 \times$. The images of surface topography were analyzed by Image-Pro Plus 6.0 in order to obtain the cell diameter.

2.3.2 Apparent density measurement. The density of samples was measured as specified in GB/T 6343-2009. The samples had a size of $50 \mathrm{~mm} \times 50 \mathrm{~mm} \times 20 \mathrm{~mm}$. The volume of each sample was measured at five spots randomly using a Vernier caliper, while the mass of the samples was weighed using an electronic balance (Shanghai PuChun Measure Instrument, China) in order to compute the apparent density.

2.3.3 Sound absorption measurement. The sound absorption of samples was measured at a frequency of $100-4000 \mathrm{~Hz}$ using a twin-microphone impedance tube (Automotive Research \& Testing Center, Taiwan) as specified in ASTM E105007 . The samples had a cylindrical shape with a diameter of 38 $\mathrm{mm}$. The air chamber size (the distance between the sample and the bottom of the tube) was $10 \mathrm{~mm}$ lengthwise. Three samples for each specification were used for the test.

2.3.4 Compressive stress test. The compressive stress of samples was measured at a tensile rate of $5 \mathrm{~mm} \mathrm{~min}^{-1}$ using a universal testing machine (HT-2402, Hong Ta Instrument, Taiwan) as specified in ASTM D1621-1. Samples were compressed to $14 \mathrm{~mm}$, which is $70 \%$ of the total thickness, at a rate of $10 \mathrm{~mm} \mathrm{~min}{ }^{-1}$. The samples had a size of $50 \mathrm{~mm} \times$ $50 \mathrm{~mm} \times 20 \mathrm{~mm}$. Five samples for each specification were used for the test.

2.3.5 Thermogravimetric analysis. Thermogravimetric analysis was conducted with a thermogravimetric analyzer (TG 209F3, NETZSCH, Germany) with dry nitrogen gas at a flow rate of $60 \mathrm{~mL} \mathrm{~min}{ }^{-1}$. The relative mass loss of the samples was recorded from $50^{\circ} \mathrm{C}$ to $700{ }^{\circ} \mathrm{C}$ at a heating rate of $10^{\circ} \mathrm{C} \mathrm{min}^{-1}$.

2.3.6 Flame retardance measurement. Both the limiting oxygen index (LOI) test and horizontal burn test were used to characterize the flame retardance properties of samples. The LOI test was conducted using a ZKHW-205 intelligent oxygen index instrument (Qingdao Zhongke Hengwei Intelligent

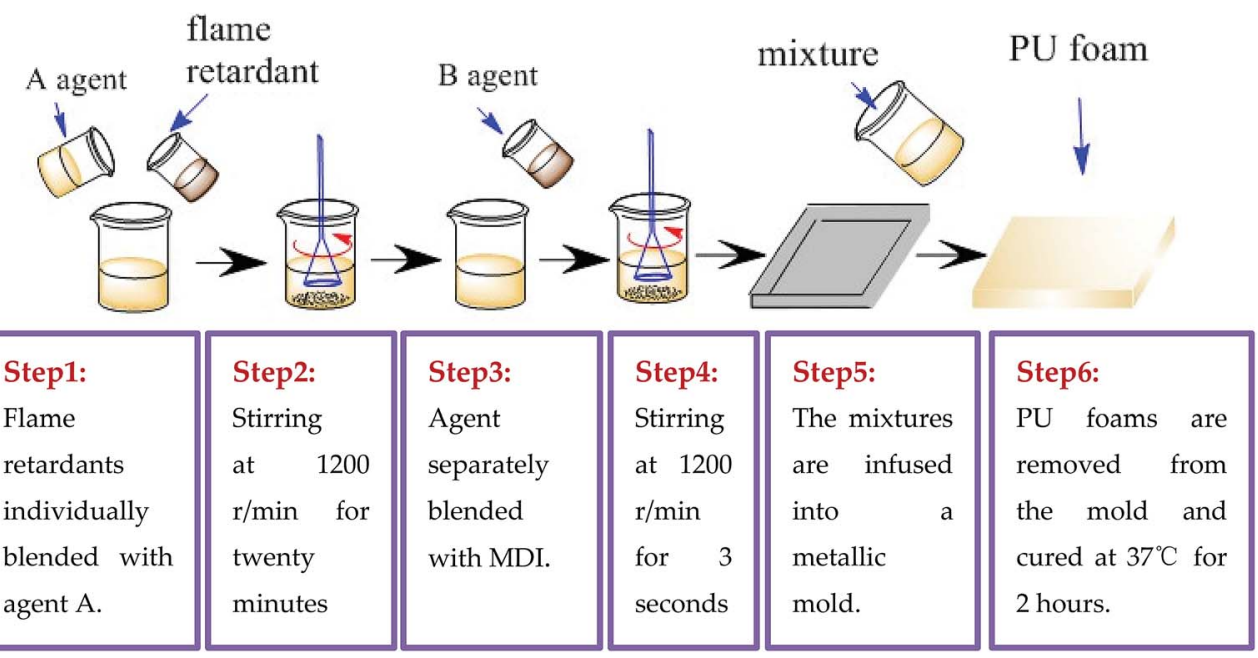

Fig. 2 Manufacturing process of the preparation of FPUF. 

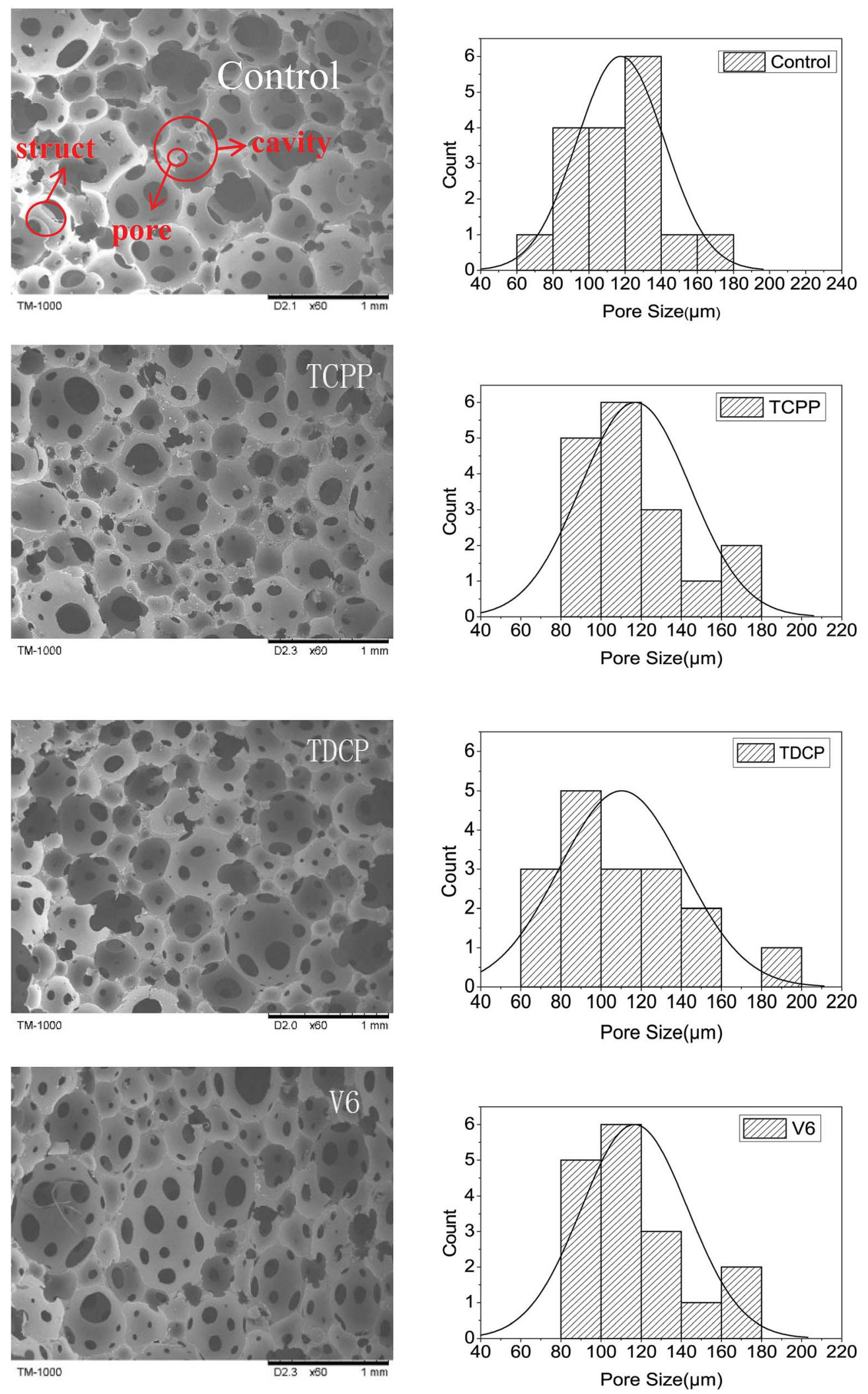

Fig. 3 SEM images (TM-1000) of FPUF composed of phosphorus flame retardants. The control group is neat FPUF.

Technology, China) according to ASTM D2863. The size of the specimens was $127 \mathrm{~mm} \times 10 \mathrm{~mm} \times 10 \mathrm{~mm}$. The horizontal burn test was conducted using a horizontal burning tester (Standard Group Ltd., Shanghai, China) as specified in GB/T 2408-2008 with a sample size of $180 \mathrm{~mm} \times$ $25 \mathrm{~mm} \times 20 \mathrm{~mm}$. 


\section{Results and discussion}

\subsection{Effect of flame retardants on cell morphology}

The cell structures of FPUFs with the addition of phosphorus flame retardants are shown in Fig. 3. The use of the liquid phosphorus flame retardants provided the FPUF with an open structure. The cells exhibited a diameter ranging between 60 and $200 \mu \mathrm{m}$. V6 caused a larger foam aperture size with a great range. The porosity was high, but the cells lacked good evenness. Compared to TCPP and V6, TDCP caused smaller cells, and the cells were compact and uniform. The difference was attributed to the surface tension and surfactant properties of the flame retardants. ${ }^{14}$ Moreover, after the addition of the flame retardants, the cell size decreased slightly, and the apparent density of FPUF correspondingly increased slightly from 0.157 to $0.160 \mathrm{~g} \mathrm{~cm}^{-3}$ (Table 3 ). This is because after the addition of the flame retardants, the viscosity of the foaming system increased, and the cell struct became thicker. ${ }^{15}$

The cell structures of FPUFs composed of both TDCP and melamine as the flame retardants are shown in Fig. 4. Increasing the content of melamine adversely affected the cell uniformity of FPUF, and the cell size and porosity thus decreased. However, with $3 \mathrm{wt} \%$ of melamine, there were no significant differences in the cells. The lower cell uniformity was ascribed to the difference between the nitrogen and phosphorus flame retardants, which in turn changed the cell structure of FPUF. The formation of cells is dependent on the viscosity and the surface tension of TDCP. ${ }^{16-19}$ In addition, Fig. 4 shows that the presence of the nitrogen/phosphorus compound flame retardant increased the cell size during foaming compared to that when only TDCP was added. This is because after the addition of the nitrogen/phosphorus compound, the nucleation efficiency improved, which in turn increased the number of bubbles..$^{20-22}$ Nevertheless, the reaction process suffered only a marginal resistance, which facilitated the formation of cells to a greater extent. ${ }^{23,24}$ Meanwhile, some small cells were ruptured and merged with others and thus, more large bubbles with openings were formed occasionally. Moreover, with the increase in the melamine content, the foam cell size decreased gradually. However, this decrease was not significant because the introduction of melamine accelerated the nucleation reaction of the foam, increased the crosslinking degree and prepolymer density, and decreased the amount of released gas. ${ }^{25}$ This insignificant decrease can also be explained by the data in Table 4. FPUFs filled with increasing melamine contents of the flame retardants showed a very small difference in apparent density.

\subsection{Effect of flame retardants on sound absorption}

The sound absorption of FPUFs in the frequency range of 0$4000 \mathrm{~Hz}$ is shown in Fig. 5. Fig. 5(a) shows that compared to the control group, FPUF containing TCPP or TDCP as the flame

Table 3 Apparent density of FPUF filled with phosphorus-based flame retardants

$\begin{array}{lllll}\text { Sample code } & \text { Control V6 } & \text { TDCP } & \text { TCPP }\end{array}$

$\begin{array}{lllll}\text { Average apparent density }\left(\mathrm{g} \mathrm{cm}^{-3}\right) & 0.157 & 0.165 & 0.162 & 0.164\end{array}$ retardant exhibited significantly higher sound absorption. This result was ascribed to an increase in the sinuosity of the sound wave propagation in FPUF. As a result, the sound absorption performance was strengthened.

The sound absorption curves of FPUFs containing 0,5 , and $10 \mathrm{wt} \%$ melamine are shown in Fig. 5(b). Regardless of the frequency, FPUF containing melamine as the flame retardant exhibited low sound absorption. The presence of melamine caused higher sound resistance of the surface, which hindered the penetration of the sound waves. Moreover, the fibers vibrated because of the sound source, and drastic vibrations dissipated the sound energy and decreased the sound absorption coefficient. The decrease in the sound absorption coefficient was attributed to the compact cell structure, which prevented the sound waves from entering the interior.

When the content of melamine increased, the sound absorption coefficient increased, which was still lower than that of the control group. Because the content of melamine reached a certain level, the nucleation became saturated in the foaming process. Excessive melamine has a negative influence on the surface sound resistance of FPUF, allowing the sound waves to penetrate FPUF and strengthening the sound absorption. ${ }^{26}$

The sound absorption curves of FPUFs that consisted of TDCP and $0,1,2,3$, or $5 \mathrm{wt} \%$ of melamine as flame retardants are shown in Fig. 5(c). At low frequencies, when the specified amount of TDCP was blended with different contents of melamine to serve as the flame retardant, a higher melamine content contributed to greater nitrogen and phosphorus synergy, which in turn increased the sound absorption coefficient of FPUF at low frequencies. Sound waves at low frequencies have a long wavelength. The nitrogen/phosphorus synergistic effect provided FPUF with an open cell structure, which enabled the penetration of sound waves of long wavelengths. By contrast, a higher melamine content decreased the sound absorption efficiency of FPUF at medium and high frequencies. The decrease was ascribed to the less uneven cell structure and the attenuated air heat viscous state. Sound waves at high frequencies have shorter wavelengths and are easily reflected and refracted. Hence, the dissipation of sound energy increased and the sound absorption coefficient of FPUF decreased. ${ }^{27}$ To sum up, when 1-3 wt\% melamine was present, the resulting FPUFs exhibited similar cell structures and thus comparable sound absorption. When the melamine content was $5 \mathrm{wt} \%$, it could be distributed in FPUF evenly, which in turn strengthened the mechanical properties of the cell walls and the frame. Due to the increase in the friction of sound waves against the cell walls and structs, the sound waves rebounded, as demonstrated in Fig. 5(d).

\subsection{Effect of flame retardants on compressive stress}

The compressive stress-strain curves of FPUF with different flame retardants are shown in Fig. 6. Fig. 6(a) shows that the use of different phosphorus flame retardants can result in comparable compressive curves, demonstrating an elastic deformation stage (stage I), a flattening stage (stage II), and a densified stage (stage III). The elastic deformation stage (stage I) occurred 

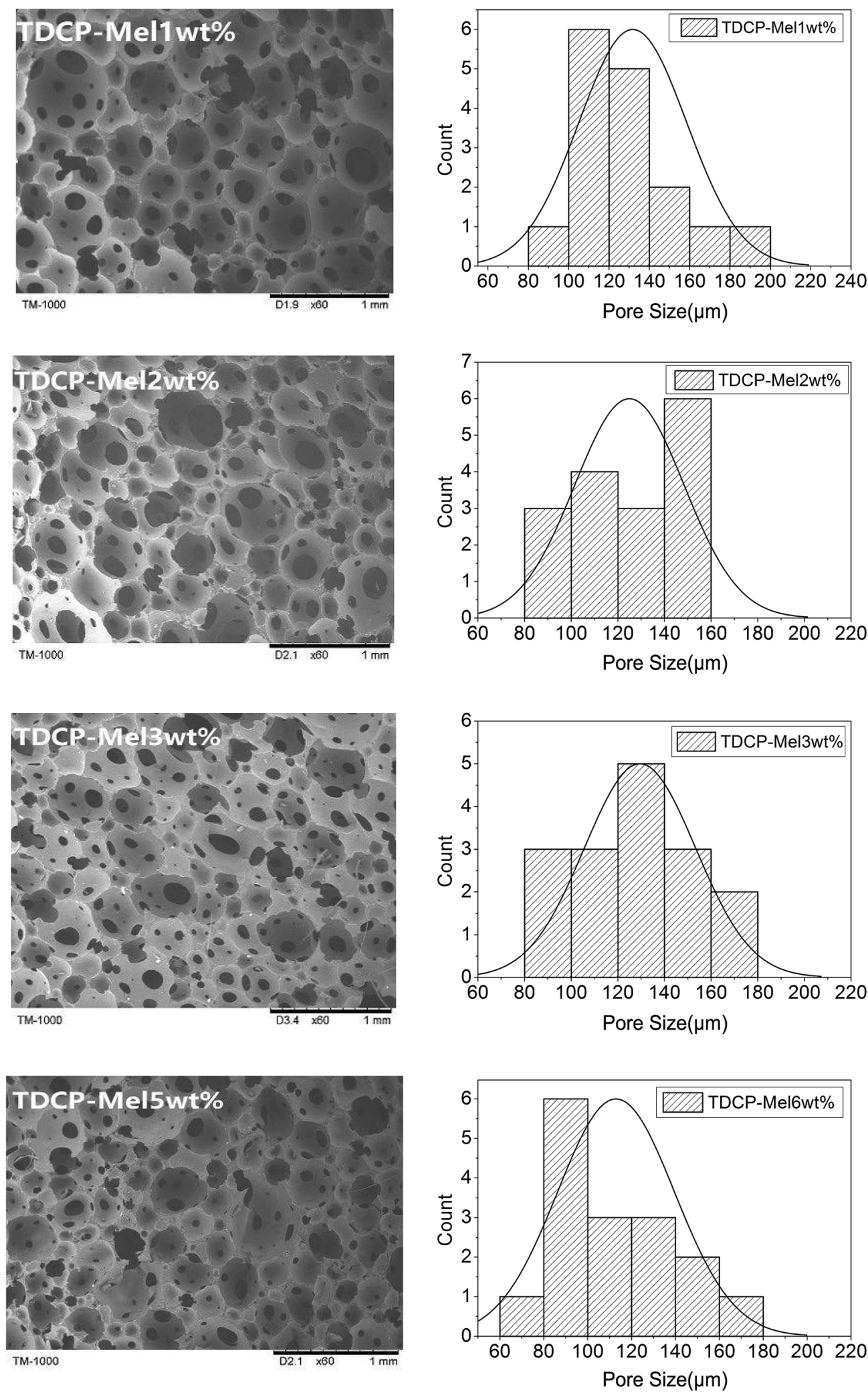

Fig. 4 SEM images of FPUF composed of both TDCP and melamine as flame retardants.

when the strain was $0-10 \%$. This stage lasted for a short time, and it was followed by the flattening stage (stage II). This phenomenon conforms to the compression results reported by
Wang et al. ${ }^{20}$ The flattening stage accounted for the major part of the whole compressive process. While FPUF underwent further elastic deformation, the interior cells exhibited drastic 
Table 4 Apparent density of FPUF filled with nitrogen/phosphorus compound flame retardants

\begin{tabular}{lllll}
\hline Sample code & P-Mel-1\% & P-Mel-2\% & P-Mel-3\% & P-Mel-5\% \\
Average apparent & 0.180 & 0.182 & 0.183 & 0.187 \\
density $\left(\mathrm{g} \mathrm{cm}^{-3}\right)$ & & & &
\end{tabular}

deformations including wall bending, torsion, and buckling mechanisms. Compared to the compressive property the control group, the compressive property of FPUF decreased as a result of the addition of flame retardants. The compressive properties could be ranked from high to low: TDCP, V6, and TCPP; the addition of the latter two resulted in similar compressive properties.

The stress-strain curves of FPUF related to the addition of 0 , 5 , and $10 \mathrm{wt} \%$ of melamine are shown in Fig. 6(b). Regardless of the content of melamine, the compressive curves were similar, showing a linear elastic zone (stage I), plastic platform area (stage II), and densified area (stage III). In particular, when the flame retardant was $5 \mathrm{wt} \%$ melamine, the compressive property of FPUF was the maximum. This result was ascribed to the fact that the number of force-bearing points increased per unit area of FPUF, which led to an increase in the total area that bears the compressive force. In addition, the interior of FPUF was compact without damaged cell walls, which helped improve the compressive properties of FPUF to a certain extent. When melamine was $10 \mathrm{wt} \%$, the compressive properties of FPUF decreased because the porosity and cell size and structs were less capable of resisting deformation. In addition, after the introduction of melamine as the flame retardant, the apparent density of the foam increased from 0.162 to $0.180 \mathrm{~g} \mathrm{~cm}^{-3}$ (Tables 3 and 4), which is the reason for the increased compressive strength. This tendency conforms to the results indicated by Wang et al. ${ }^{23}$

The stress-strain curves of FPUF related to a specified amount of TDCP and $0,1,2,3$, and $5 \mathrm{wt} \%$ of melamine are shown in Fig. 6(c). The curves were comparable, demonstrating the linear elastic stage (stage I), elastic platform stage (stage II), and densified stage (stage III). Furthermore, the compressive properties of FPUF were proportional to the content of melamine. Specifically, the combination of a specified amount of TDCP and $5 \mathrm{wt} \%$ of melamine as the flame retardant increased the compressive properties of elastic FPUF by 3.4 times. Melamine was dispersed evenly in the cells and thereby strengthened the cell walls and structs, increasing the force-bearing points and the total area to withstand the force. The compact foam interior and intact cell walls then improved the compressive properties of FPUF. Fig. 6(d) also proves the above findings that the combination of TDCP and melamine significantly improves the mechanical properties of FPUF.

\subsection{Thermogravimetric analysis (TGA)}

The TGA curves of FPUFs, where the control group is neat FPUF without a flame retardant, are shown in Fig. 7. When the samples were heated from $50{ }^{\circ} \mathrm{C}$ to $700{ }^{\circ} \mathrm{C}$, the control group exhibited the lowest carbon residue amount. Moreover, FPUF containing the nitrogen and phosphorus synergistic flame retardant showed the greatest amount of carbon residue. This indicated that the addition of the flame retardant has a significant effect on the degradation of FPUF and leads to an increase
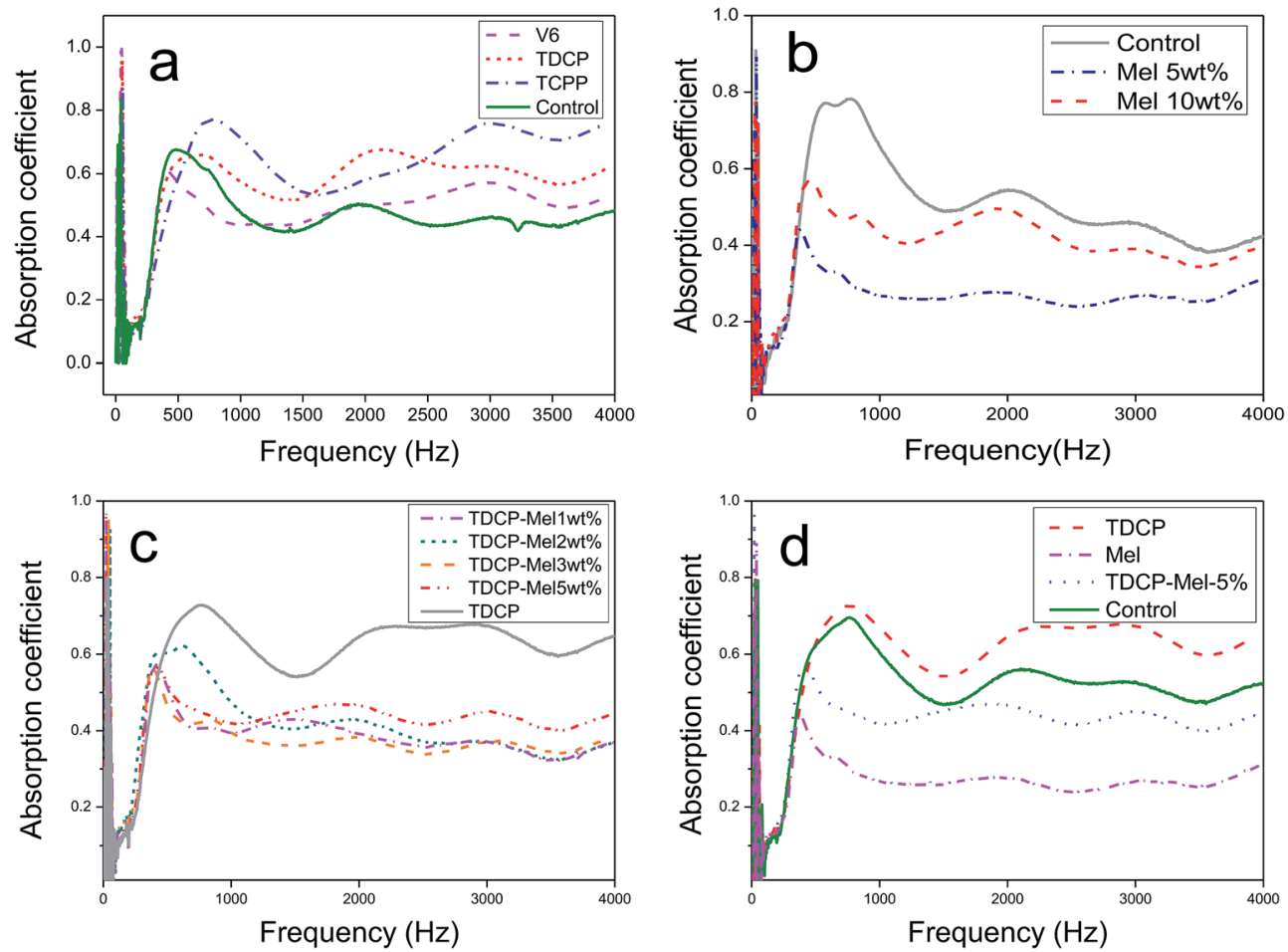

Fig. 5 Sound absorption of FPUF composed of (a) phosphorus, (b) melamine, and (c) nitrogen/phosphorus flame retardants. (d) Comparison of combustion resistance. 

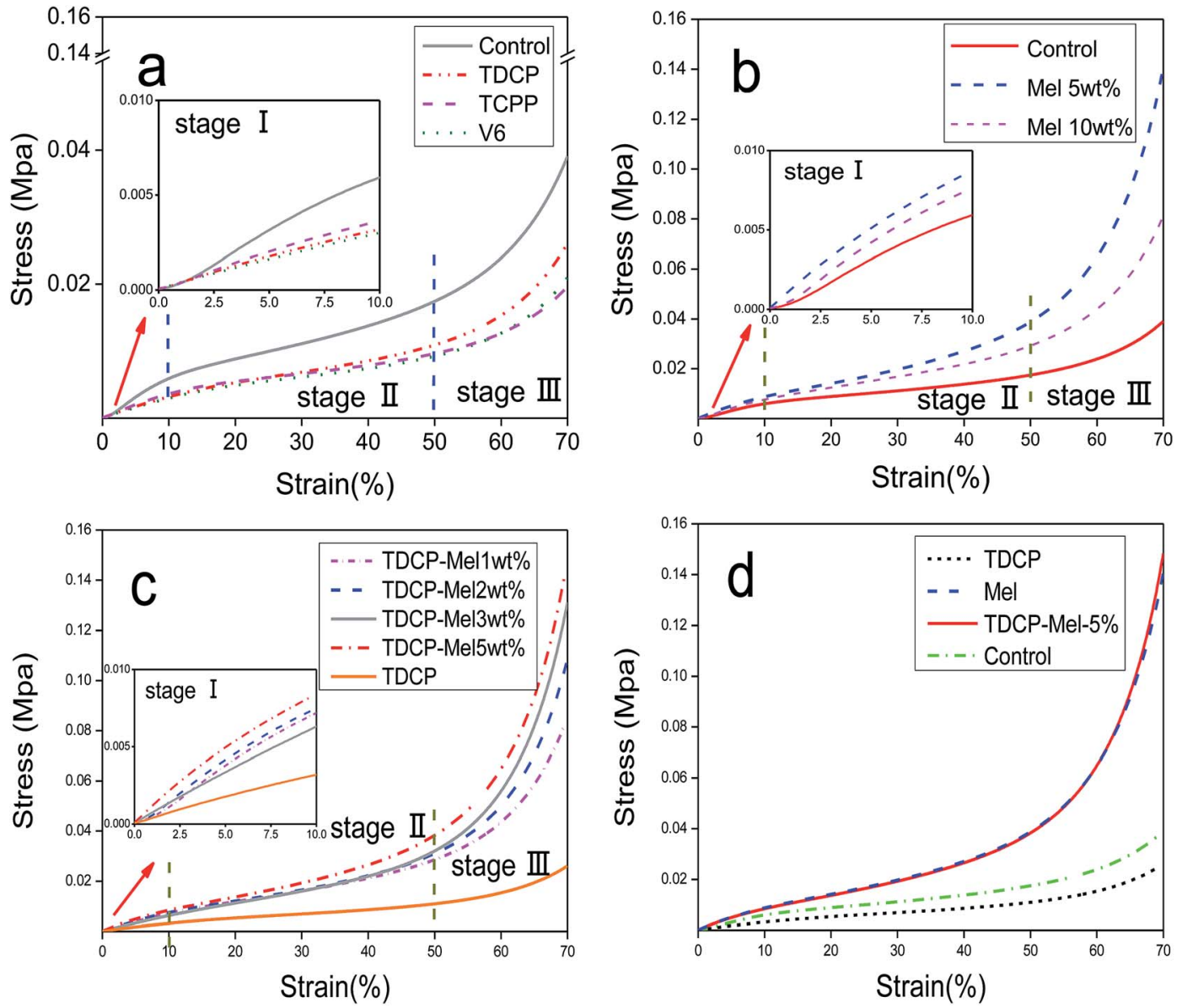

Fig. 6 Stress-strain curves of FPUF composed of (a) phosphorus, (b) melamine, and (c) phosphorus/melamine flame retardants. (d) Stress-strain curves of FPUF with different flame retardants.

in the amount of carbon residue. In addition, after the addition of the flame retardant, the initial degradation temperature $\left(T_{5 \%}\right)$ increased, indicating that the flame retardant can improve the thermal stability of the PU foam. This is because a flame retardant after degradation produces a non-reactive gas, which dilutes the concentration of the reactive gas, thereby

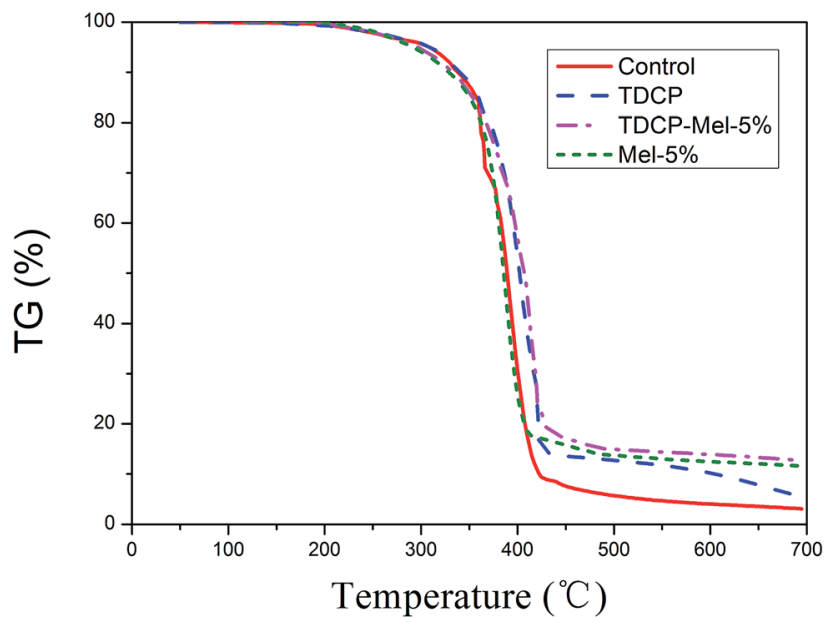

Fig. 7 TGA curves of FPUF related to without (control), TDCP, TDCPMel- $5 \%$, and Mel- $5 \%$ flame retardants.

suppressing the flammability and the decomposition degree of FPUF. However, this improvement was not obvious; the maximum difference between the temperatures for $5 \%$ mass loss was about $5{ }^{\circ} \mathrm{C}$, whereas for $50 \%$ mass loss, it was even less. As a result of heating, the phosphorus flame retardant formed phosphates, which accelerated the formation of carbon layers. After the completion of the TGA test, the carbon residue

Table 5 TGA analysis results

\begin{tabular}{llll}
\hline & $\begin{array}{l}\text { Temperature for } \\
\text { Sample }\end{array}$ & $\begin{array}{l}\text { Temperature for } \\
50 \% \text { mass loss }\end{array}$ & Residual mass \\
\hline Control & $291.6{ }^{\circ} \mathrm{C}$ & $387.1{ }^{\circ} \mathrm{C}$ & $3.1 \%$ \\
TDCP & $293.3^{\circ} \mathrm{C}$ & $390.9^{\circ} \mathrm{C}$ & $5.3 \%$ \\
Mel5\% & $294.5{ }^{\circ} \mathrm{C}$ & $389.4{ }^{\circ} \mathrm{C}$ & $11.2 \%$ \\
TDCP-Mel5\% & $296.6{ }^{\circ} \mathrm{C}$ & $391.0^{\circ} \mathrm{C}$ & $12.2 \%$
\end{tabular}

Table 6 LOI of FPUF made of different flame retardants

Sample

. 

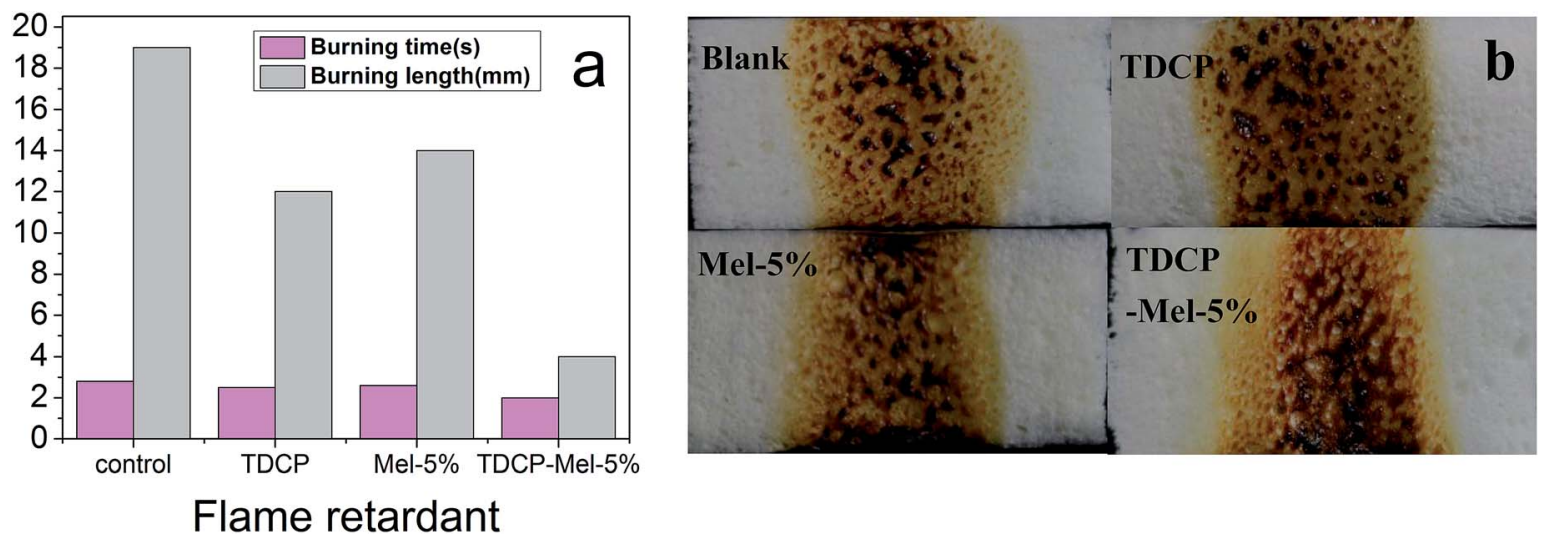

Flame retardant

Fig. 8 (a) Burning time and length after the horizontal burning test; (b) residue morphology of the samples after the combustion of FPUFs filled with different flame retardants.

morphology of each sample was observed. In the polyurethane foam without the addition of the flame retardant, the surface of the carbon residue was continuous and dense. After the addition of the flame retardant, the flame retardant degraded to form a fluffy material covering the surface of the carbon residue, and highly cross-linked polyphosphoric acid formed during degradation covered the surface of the carbon residue, resulting in a more compact carbon residue during the combustion process. ${ }^{28}$ It could block the thermal insulation and the propagation of flammable gases to the PU foam substrate. After the addition of melamine, a worm-like fluffy carbon layer was formed, which effectively shielded the insulating interlayer, thereby providing an excellent flame retardant effect (Table 5). ${ }^{29}$

\subsection{Combustion resistance}

The limiting oxygen index (LOI) values of FPUF containing the flame retardant TDCP or TDCP/melamine are shown in Table 6 . The control group was neat FPUF. The control group could be easily ignited under atmospheric conditions. Using TDCP as the flame retardant provided FPUF with LOI of 24; the use of TDCP and melamine as flame retardants provided FPUF with LOI of 25.5. This observation shows that the presence of the nitrogen and phosphorus synergistic flame retardant strengthens the mechanical properties, sound absorption, and combustion resistance of FPUF.

The results of the horizontal flame tests of the samples after the addition of different flame retardants are shown in Fig. 8(a). Obviously, after the addition of the flame retardant, the burning length was reduced, and the burning time was lowered. On adding TDCP and 5\% melamine flame retardants, the burning length and burning time were lowered to $4 \mathrm{~mm}$ and $2 \mathrm{~s}$, respectively. Fig. 8 (b) shows the residue morphology of the sample after combustion. After the addition of the flame retardant, the amount of residue increased, and the amount of molten drips during combustion also significantly increased. Therefore, the presence of the nitrogen/phosphorus synergistic flame retardant not only reinforced the compression strength of FPUF but also improved the combustion resistance. This is because the introduction of the nitrogen-phosphorus compound flame retardant enhanced the initial thermal degradation temperature of the polyurethane polymer, released more amounts of non-flammable gases due to the thermal pyrolysis of alcohols and thermal oxidation of unstable structures in the carbon layer, and generated more carbon residues. ${ }^{30}$ As seen from Fig. 8(b), the addition of the nitrogen-phosphorus compound flame retardant results in the largest amount of sample residues after combustion, and maximum molten drips are also observed. The nitrogen-phosphorus compound flame retardant accelerated the formation of metaphosphoric or pol$y$ (phosphoric acid) due to thermal degradation. These acid substances then promoted char formation via polymer dehydration, and poly(phosphoric acid) covering the surface of the carbon residue layer further inhibited the thermal oxidation of the char layer. This process also released a non-flammable gas, which diluted the flammable gas concentration, retarded the spread of combustion, and facilitated the formation of a fluffy carbon layer. ${ }^{30}$ When the molten material was dropped, a large amount of heat was released, which lowered the temperature of the burning sample and then enhanced the flame retardant effect. ${ }^{31}$ Besides, these molten drips also covered the surface of other materials, preventing the burning gas from entering the materials and inhibiting further combustion.

\section{Conclusion}

Phosphorus, nitrogen, and nitrogen/phosphorus synergistic flame retardants were added during the preparation of FPUF. As for the phosphorus flame retardants, the presence of V6 caused the biggest cell size, highest porosity and lowest mechanical properties of FPUF, while the presence of TDCP and TCPP caused comparable cell sizes, porosities, and mechanical properties. As for the melamine flame retardant, the compressive performance of FPUF first increased and then decreased. Regardless of the content of melamine, the compressive strength of FPUF was greater than that of the control group. As for the nitrogen/phosphorus synergistic flame retardant melamine-TDCP, the cell size of FPUF was small. Melamine was not soluble and thus, it could accelerate the nucleation reaction and improve the degree of cross-linking. Therefore, the density of the prepolymer increased, which in turn caused lower air 
emission, smaller cell size, and lower sound absorption. However, when a specified amount of TDCP and $5 \mathrm{wt} \%$ melamine were used, melamine could be distributed evenly in FPUF, thereby strengthening the cell walls and frames as well as the friction of sound waves against the cell walls and structs. Therefore, the resultant FPUF exhibited higher sound absorption. Neat FPUF could be ignited easily. On comparing TDCP with the nitrogen/phosphorus synergistic flame retardant melamine-TDCP, we inferred that the latter provided FPUF with greater thermal decomposition and higher LOI.

\section{Author contributions}

In this study, the concepts and designs for the experiments were supervised by A/Prof. Ting-Ting Li and Prof. Jia-Horng Lin. Text composition and result analysis were performed by A/Prof. Shih-Yu Huang and Mengfan Xing. Experiments and data processing were conducted by Mengfan Xing, Hongyang Wang and Chengeng $\mathrm{Fu}$. The experimental results and analysis were examined by Prof. Ching-Wen Lou, A/Prof. Ting-Ting Li and A/ Prof. Shih-Yu Huang.

\section{Conflicts of interest}

The authors declare no conflict of interest.

\section{Acknowledgements}

This work is supported by the Open Project Program of Fujian Key Laboratory of Novel Functional Fibers and Materials (Minjiang University), China (No. FKLTFM1710, FKLTFM 1722), the Natural Science Foundation of Tianjin (18JCQNJC03400), the Natural Science Foundation of Fujian (2018J01504, 2018J01505) and the National Natural Science Foundation of China (grant number 11702187). This study is also supported by the Opening Project of Green Dyeing and Finishing Engineering Research Center of Fujian University (2017001A, 2017001B, and 2017002B) and the Program for Innovative Research Team in University of Tianjin (TD13-5043).

\section{References}

1 P. Chen, Y. Zhao, W. Wang, T. Zhang and S. Song, Polymers, 2019, 11(2), 22-31.

2 H. Choe, G. Sung and J. H. Kim, Compos. Sci. Technol., 2018, 156, 19-27.

3 S. X. Wang, H. B. Zhao, W. H. Rao, S. C. Huang, T. Wang, W. Liao and Y. Z. Wang, Polym. Rev., 2018, 153, 616-625.

4 W. H. Rao, Z. M. Zhu, S. X. Wang, T. Wang, Y. Tan, W. Liao, H. B. Zhao and Y. Z. Wang, Polym. Degrad. Stab., 2018, 153, 192-200.

5 S. Wang, X. Du, Y. Jiang, J. Xu, M. Zhou, H. Wang, X. Cheng and Z. Du, J. Colloid Interface Sci., 2018, 146, 18-27.

6 R. Yang, B. Wang, X. Han, B. Ma and J. Li, Polym. Degrad. Stab., 2017, 144, 62-69.
7 S. T. McKenna and T. R. Hull, Fire Sci. Rev., 2016, 5(1), 57-66. 8 S. Bhoyate, M. Ionescu, P. K. Kahol, J. Chen, S. R. Miahra and R. K. Gupta, J. Appl. Polym. Sci., 2018, 135(21), 46224.

9 M. J. Chen, C. R. Chen, Y. Tan, J. Q. Huang, X. L. Wang, L. Chen and Y. Z. Wang, Ind. Eng. Chem. Res., 2014, 53(3), 1160-1171.

10 W. H. Rao, H. X. Xu, Y. J. Xu, M. Qi, W. Liao, S. Xu and Y. Z. Wang, Chem. Eng. J., 2018, 343, 198-206.

11 W. H. Rao, Z. M. Zhu, S. X. Wang, T. Wang, Y. Tan, W. Liao, H. B. Zhao and Y. Z. Wang, Polym. Degrad. Stab., 2018, 153, 192-200.

12 D. M. Chen, Y. P. Zhao, J. J. Yan, L. Chen, Z. Z. Dong and W. G. Fu, Adv. Mater., 2011, 418, 540-543.

13 B. Czuprynski, J. Paciorek-Sadowska and J. Liszkowska, J. Appl. Polym. Sci., 2010, 115, 2460-2469.

14 H. Choe, G. Sung and J. H. Kim, Compos. Sci. Technol., 2018, 156, 19-27.

15 J. G. Gwon, S. K. Kim and J. H. Kim, Mater. Des., 2016, 89, 448-454.

16 M. Marvi-Mashhadi, C. S. Lopes and J. Llorca, Mech. Mater., 2018, 124, 143-154.

17 X. Chen, L. Huo, C. Jiao and S. Li, J. Anal. Appl. Pyrolysis, 2013, 100, 186-191.

18 M. Zhang, Z. Luo, J. Zhang, S. Chen and Y. Zhou, Polym. Degrad. Stab., 2015, 120, 427-434.

19 Y. Yuan, C. Ma, Y. Shi, L. Song, Y. Hu and W. Hu, Mater. Chem. Phys., 2018, 211, 42-53.

20 S. X. Wang, H. B. Zhao, W. H. Rao, S. C. Huang, T. Wang, W. Liao and Y. Z. Wang, Polym. Rev., 2018, 153, 616-625.

21 M. Zhang, J. Zhang, S. Chen and Y. Zhou, Polym. Degrad. Stab., 2014, 110, 27-34.

22 J. C. Yang, Z. J. Cao, Y. Z. Wang and D. A. Schiraldi, Polym. Rev., 2015, 66, 86-93.

23 S. Wang, X. Du, Y. Jiang, J. Xu, M. Zhou, H. Wang, X. Cheng and Z. Du, J. Colloid Interface Sci., 2018, 57, 18-25.

24 S. Y. Liang, Polym. Degrad. Stab., 2012, 97(11), 2428-2440.

25 S. Gaan, S. Liang, H. Mispreuve, H. Perler, R. Naescher and M. Neisius, Polym. Degrad. Stab., 2015, 113, 180-188.

26 H. Xie, W. Yang, A. C. Y. Yuen, C. Xie, J. Xie, H. Lu and G. H. Yeoh, Chem. Eng. J., 2017, 311, 310-317.

27 H. Liao, H. Li, Y. Liu and Q. Wang, Polym. Int., 2019, 68(3), 410-417.

28 H. K. Peng, X. X. Wang, T. T. Li, S. Y. Huang, Q. Lin, B. C. Shiu, C. W. Lou and J. H. Lin, $R S C A d v ., 2018,8(58)$, 33542-33550.

29 X. Du, J. Li, S. Wang, H. Wang, X. Cheng and Z. Du, Thermochim. Acta, 2018, 670, 55-60.

30 X. P. Hu, Y. Y. Guo, L. Chen, X. L. Wang, L. J. Li and Y. Z. Wang, Polym. Degrad. Stab., 2012, 97, 1772-1778.

31 L. W. Wu, J. Y. Ban, Q. Jiang, T. T. Li, B. C. Shiu, H. K. Peng, S. Y. Huang, C. W. Lou and J. H. Lin, J. Appl. Polym. Sci., 2018, 135(48), 46871-46879. 